\title{
Postoperative morbidity in elderly patients after gastric cancer surgery
}

\author{
Tomoyuki Wakahara, Nozomi Ueno, Tetsuo Maeda, Kiyonori Kanemitsu, Takuro Yoshikawa, \\ Shinobu Tsuchida, Akihiro Toyokawa
}

Yodogawa Christian Hospital, Osaka, Japan

\section{Abstract}

\section{Introduction}

In recent years, life expectancy has increased worldwide and the proportion of elderly people is increasing, especially in advanced countries [1]. Japan is becoming a "graying" society at a rate unprecedented in the world. According to the Statistics Bureau, Ministry of Internal Affairs and Communications of Japan, the estimated proportion of aged residents ( $\geq 65$ years) in 2017 is $27.8 \%$ [2], and this proportion is expected to increase in the future [1].

Department of Surgery, Yodogawa Christian Hospital, Osaka, Japan

Correspondence to: Tomoyuki Wakahara, Department of Surgery, Yodogawa Christian Hospital, 1-7-50, Kunijima, Higashi Yodogawa Ku, Osaka 533-0024, Japan, e-mail: wakkan@mail.goo.ne.jp

Conflict of Interest: None

Received 12 January 2018; accepted 22 April 2018; published online 9 May 2018

DOI: https://doi.org/10.20524/aog.2018.0274
Gastric cancer is a common malignancy in Japan. More than 132,000 patients were newly diagnosed with gastric cancer in 2011 and this disease was the third leading cause of cancerrelated deaths in 2014 [3]. Surgical resection is the mainstay of gastric cancer treatment. Improvements in perioperative care skills, anesthesia, and surgical techniques and devices have increased the reliability and safety of surgery; as a result, the number of elderly patients who undergo surgery has increased. Surgical resection appears to be beneficial and feasible even for elderly patients [4], and the overall survival of elderly patients with gastric cancer who undergo surgery was significantly better than the survival of patients who received only best supportive care, especially among patients with advanced gastric cancers [5].

Aging is accompanied by a gradual decrease in physiological reserves in various organ systems, including the endocrine, immune, respiratory, cardiovascular and renal systems, ultimately resulting in frailty or a state of increased vulnerability to poor resolution of homeostasis after a stressful event in elderly people [6]. Accordingly, elderly people have an increased risk of adverse outcomes after surgery. Chronological 
age is an important factor to consider when determining treatment strategies, although heterogeneity in the aging process should also be acknowledged. Therefore, the detection of predictive factors of postoperative morbidity is an essential step prior to providing invasive treatment for elderly patients.

In this study, we reviewed the clinicopathological data of patients who underwent surgery for gastric cancer to evaluate the short-term outcomes and determine factors predictive of postoperative complications.

\section{Patients and methods}

A total of 565 consecutive patients underwent elective surgery for primary gastric cancer at Yodogawa Christian Hospital between January 2007 and December 2015. Twentyone patients were excluded from this study: 5 who underwent pancreatoduodenectomy because of duodenal invasion, comorbid pancreatic cancer, or cholangiocarcinoma; 12 who underwent gastrectomy for remnant stomach cancer; and 4 who underwent palliative partial gastrectomy. The short-term postoperative outcomes of the remaining 544 patients were studied.

The patients' medical records and operative reports were reviewed retrospectively and clinicopathological information was obtained for each patient. Postoperative complications were evaluated using the Clavien-Dindo classification [7], and those with grade $\geq$ II were included in the analysis. When a patient had $\geq 2$ complications, the highest grade among the complications was recorded.

Treatment strategy for individual patients was decided in a preoperative conference that always involved 5-10 surgeons, while gastroenterologists, endoscopists, radiologists and/or medical oncologists were also involved in complicated cases.

In most cases, surgery was performed by one of three experienced, specialized upper gastrointestinal surgeons. Surgery performed by other surgeons, including residents, was supervised by at least one of these three surgeons. Surgical procedures and pathological results were assessed according to the Japanese classification of gastric carcinoma, third English edition [8]. The extent of lymph node dissection was defined according to the 2010 Japanese gastric cancer treatment guidelines (ver. 3) [9]. In cases of total gastrectomy, D2 lymph node dissection without dissection of the No. 10 lymph nodes was classified as D2.

The protocol was approved by the institutional ethics committee on human experimentation and was in accordance with the Helsinki Declaration of 1964 and later versions. Informed consent or a substitute for it was obtained from all patients for their inclusion in the study.

\section{Definition of an elderly person}

According to the World Health Organization, most developed countries accept a cutoff of 65 years of age as the definition of an "elderly" person, although no general consensus has been reached [10]. However, the Statistics Bureau, Ministry of Internal Affairs and Communications of Japan has reported that in Japan, $52.2 \%$ of men and $31.6 \%$ of women aged 65 69 years are still working [11], which indicates that many people in this age group have maintained their fitness and quality of life; accordingly, an age cutoff of 65 years seemed too young with regard to the elderly. Therefore, we used a cutoff age of 70 years and divided patients into two groups: the elderly group, or those aged $\geq 70$ years, and the control group, or those aged $<70$ years.

\section{Statistical analysis}

Comparisons of the proportions or frequencies between the two groups were performed using Fisher's exact test or the chisquare test, and differences in continuous variables such as age, blood loss volume, and laboratory parameters were evaluated using the Mann-Whitney $U$-test. Valuables with P-values $<0.05$ in the univariate analysis were included in the multivariate regression analysis to identify the risk factors for postoperative complications. The cutoff values of continuous valuables were identified via receiver operating characteristic curve analysis. All statistical analyses were performed using JMP software 12.2.0 (SAS Institute Inc., Cary, NC, USA).

\section{Results}

The clinicopathological characteristics of the 544 patients with primary gastric cancer who underwent elective gastrectomy are listed in Table 1 . The elderly and control groups consisted of 282 and 262 patients, respectively. More patients in the elderly group had comorbidities such as hypertension, hyperlipidemia, and diabetes mellitus $(\mathrm{P}<0.001)$. This group also had a significantly higher proportion of patients with an American Society of Anesthesiologists Physical Status (ASA PS) class of 3 or $4(\mathrm{P}<0.001)$. The elderly group had a statistically lower serum hemoglobin level and estimated glomerular filtration rate and a worse nutritional status. The frequency of open surgery was higher in the elderly group $(\mathrm{P}<0.001)$. The groups did not differ significantly in terms of body mass index; type of gastrectomy; extent of lymph node dissection; rate of combined resection of spleen, pancreas, or gallbladder; amount of blood loss during surgery; and pathological gastric cancer stage distribution.

Table 2 shows the incidence of the postoperative complications in detail. Seventy patients in the elderly group and 35 in the control group had 1 or more complications of grade II or higher according to the Clavien-Dindo classification. The respective overall morbidity rates were $24.8 \%$ and $13.4 \%$, a statistically significant difference $(\mathrm{P}<0.001)$. The incidence of anastomotic leakage, including duodenal stump leakage, was significantly higher in the elderly group $(\mathrm{P}=0.039)$. Although the elderly group also had relatively higher incidences of cardiovascular complications such as brain infarction or pulmonary embolism, these differences were not significant $(\mathrm{P}=0.053$ and $\mathrm{P}=0.094$, 
Table 1 Characteristics of the patients

\begin{tabular}{|c|c|c|c|}
\hline Characteristic & $\begin{array}{l}\text { Elderly } \\
\text { group }\end{array}$ & $\begin{array}{l}\text { Control } \\
\text { group }\end{array}$ & P-value \\
\hline $\mathrm{n}$ & 282 & 262 & \\
\hline Age * & $76.4 \pm 4.6$ & $59.2 \pm 8.1$ & $<0.001$ \\
\hline Sex & & & 0.645 \\
\hline Male & 194 & 185 & \\
\hline Female & 88 & 77 & \\
\hline BMI $\left(\mathrm{kg} / \mathrm{m}^{2}\right)$ & $22.6 \pm 3.2$ & $22.7 \pm 3.2$ & 0.858 \\
\hline Comorbidity & $223(79.1 \%)$ & $143(54.6 \%)$ & $<0.001$ \\
\hline \multirow[t]{3}{*}{ ASA PS } & & & $<0.001$ \\
\hline & 1,2 & 221 & 234 \\
\hline & 3,4 & 61 & 28 \\
\hline \multicolumn{4}{|l|}{ Laboratory data } \\
\hline Hemoglobin $(\mathrm{g} / \mathrm{dL})^{*}$ & $11.9 \pm 1.9$ & $12.8 \pm 2.2$ & $<0.001$ \\
\hline $\begin{array}{l}\text { eGFR }(\mathrm{mL} / \mathrm{min} / \\
\left.1.73 \mathrm{~m}^{2}\right)^{*}\end{array}$ & $68.5 \pm 17.9$ & $75.7 \pm 19.2$ & $<0.001$ \\
\hline Albumin $(\mathrm{g} / \mathrm{dL})^{*} \dagger$ & $3.8 \pm 0.6$ & $4.1 \pm 0.5$ & $<0.001$ \\
\hline Lymphocytes $($ cells $/ \mu \mathrm{L}) *$ & $1613 \pm 600$ & $1874 \pm 676$ & $<0.001$ \\
\hline Type of gastrectomy & & & 0.103 \\
\hline DG, PPG, PG & 192 & 195 & \\
\hline TG & 90 & 67 & \\
\hline Lymph node dissection & & & 0.750 \\
\hline D0, D1, D1+ & 135 & 129 & \\
\hline D2 & 147 & 133 & \\
\hline Approach & & & $<0.001$ \\
\hline Open & 215 & 155 & \\
\hline Laparoscopy & 67 & 107 & \\
\hline \multicolumn{4}{|l|}{ Combined Resection } \\
\hline Spleen and/or pancreas & $35(12.4 \%)$ & $28(10.7 \%)$ & 0.530 \\
\hline Gall bladder & $65(23.0 \%)$ & $52(19.8 \%)$ & 0.364 \\
\hline Blood loss $(\mathrm{mL})^{*}$ & $248.8 \pm 290.0$ & $235.7 \pm 285.6$ & 0.317 \\
\hline pStage & & & 0.110 \\
\hline IA & 103 & 130 & \\
\hline IB & 39 & 32 & \\
\hline IIA & 27 & 22 & \\
\hline IIB & 21 & 15 & \\
\hline IIIA & 16 & 14 & \\
\hline IIIB & 27 & 13 & \\
\hline IIIC & 16 & 13 & \\
\hline IV & 33 & 23 & \\
\hline
\end{tabular}

* Data are presented as means \pm standard deviations,

$\dagger$ Serum albumin level data are missing for 11 patients in the elderly group and 7 patients in the control group

BMI, body mass index; ASA PS, American Society of Anesthesiologists Physical Status; eGFR, estimated glomerular filtration rate; $D G$, distal gastrectomy; PPG, pylorus-preserving gastrectomy; $P G$, proximal gastrectomy; TG, total gastrectomy; DM, diabetes mellitus
Table 2 Postoperative morbidity

\begin{tabular}{|c|c|c|c|}
\hline Morbidity & $\begin{array}{l}\text { Elderly } \\
\text { group }\end{array}$ & $\begin{array}{l}\text { Control } \\
\text { group }\end{array}$ & P-value \\
\hline Overall & $70(24.8 \%)$ & $35(13.4 \%)$ & $<0.001$ \\
\hline Bleeding & $5(1.8 \%)$ & $5(1.9 \%)$ & 0.907 \\
\hline Brain infarction & $4(1.4 \%)$ & $0(0 \%)$ & 0.053 \\
\hline $\begin{array}{l}\text { Pulmonary } \\
\text { embolism }\end{array}$ & $3(1.1 \%)$ & $0(0 \%)$ & 0.094 \\
\hline $\begin{array}{l}\text { Anastomotic } \\
\text { leakage* }\end{array}$ & $13(4.6 \%)$ & $4(1.5 \%)$ & 0.039 \\
\hline Pancreatic fistula & $13(4.6 \%)$ & $11(4.2 \%)$ & 0.815 \\
\hline Pneumonia & $8(2.8 \%)$ & $5(1.9 \%)$ & 0.479 \\
\hline Wound infection & $3(1.1 \%)$ & $1(0.38 \%)$ & 0.352 \\
\hline $\begin{array}{l}\text { Intraabdominal } \\
\text { abscess }\end{array}$ & $7(2.5 \%)$ & $5(1.9 \%)$ & 0.649 \\
\hline Other infections ${ }^{\dagger}$ & $5(1.8 \%)$ & $3(1.1 \%)$ & 0.543 \\
\hline $\begin{array}{l}\text { Fever of unknown } \\
\text { origin }^{*}\end{array}$ & $5(1.8 \%)$ & $4(1.5 \%)$ & 0.822 \\
\hline Ileus & $2(0.71 \%)$ & $0(0 \%)$ & 0.172 \\
\hline Others & $9(3.2 \%)$ & $4(1.5 \%)$ & 0.297 \\
\hline $\begin{array}{l}\text { Infectious } \\
\text { complication }^{\S}\end{array}$ & $26(9.2 \%)$ & $17(6.5 \%)$ & 0.238 \\
\hline $\begin{array}{l}\text { Cardiovascular } \\
\text { complication" }\end{array}$ & $7(2.5 \%)$ & $0(0 \%)$ & 0.01 \\
\hline $\begin{array}{l}\text { Grade of } \\
\text { complications }\end{array}$ & & & 0.538 \\
\hline II & $44(15.6 \%)$ & $20(7.6 \%)$ & \\
\hline IIIa & $16(5.7 \%)$ & $9(3.4 \%)$ & \\
\hline IIIb & $3(1.1 \%)$ & $3(1.1 \%)$ & \\
\hline IVa & $3(1.1 \%)$ & $1(0.38 \%)$ & \\
\hline $\mathrm{IVb}$ & $1(0.35 \%)$ & $2(0.76 \%)$ & \\
\hline V & $3(1.1 \%)$ & $0(0 \%)$ & \\
\hline$\geq$ IIIa & $26(9.2 \%)$ & $15(5.7 \%)$ & 0.123 \\
\hline
\end{tabular}

Complications of grade II or higher (Clavien-Dindo) classification are included in the table

*Anastomotic leakage includes duodenal stump leakage

${ }^{\dagger}$ Other infections include catheter-related bloodstream infection, urinary tract infection, pseudomembranous colitis, and others

${ }^{*}$ For cases with fever of unknown origin, the cause could not be confirmed using clinical exams or images; however, antibiotics were administered for suspected intraabdominal or pulmonary infections.

'Infectious complications include pneumonia, wound infections, intraabdominal abscess, other infections, and fever of unknown origin; however, several patients had multiple infectious complications, and the number of cases is not the sum of each infectious complication

"Cardiovascular complications include brain infarction and pulmonary infarction

'Clavien-Dindo classification

respectively). However, when these conditions were combined as cardiovascular complications, a significant difference was observed between the groups $(\mathrm{P}=0.01)$. The distribution of 
complication severity was similar between the groups $(\mathrm{P}=0.538)$ and there was no significant difference in the incidence of severe (grade III or higher) complications $(\mathrm{P}=0.123)$.

In a univariate analysis, male sex $(\mathrm{P}=0.020)$, total gastrectomy $(\mathrm{P}=0.049)$ and a blood loss volume of $\geq 320 \mathrm{~mL}$ $(\mathrm{P}<0.001)$ were identified as significant predictive factors for overall morbidity after elective gastrectomy among elderly patients (Table 3). Multivariate analysis identified only a blood loss volume of $\geq 320 \mathrm{~mL}$ as an independent predictive factor of overall morbidity (odds ratio [OR], 2.538; 95\% confidence interval [CI] 1.344-4.811; $\mathrm{P}=0.004$; Table 4).
Because the frequencies of anastomotic leakage and cardiovascular complication were significantly higher in the elderly group, we further analyzed the clinicopathological factors associated with these complications. The univariate analysis identified an ASA PS class of 3 or 4 as the only significant predictive factor of postoperative cardiovascular complications $(\mathrm{P}=0.001)$, and this factor was also confirmed in a multivariate regression model $(\mathrm{P}=0.006$; Table 5$)$. Regarding anastomotic leakage, an age of $\geq 78$ years $(\mathrm{P}=0.017)$, open surgery $(\mathrm{P}=0.039)$ and a blood loss of $\geq 219 \mathrm{~mL}(\mathrm{P}<0.001)$ were identified as predictive factors in the univariate analysis;

Table 3 Univariate analysis of the relationships of overall morbidity with clinical characteristics among elderly patients

\begin{tabular}{|c|c|c|c|}
\hline Characteristic & Complication $(+)$ & Complication (-) & $\mathrm{P}$-value \\
\hline $\mathrm{n}$ & $70(24.8 \%)$ & $212(75.2 \%)$ & \\
\hline Age $^{*}$ & $77.0 \pm 4.6$ & $76.2 \pm 4.6$ & 0.166 \\
\hline Sex & & & 0.020 \\
\hline Male & 56 & 138 & \\
\hline Female & 14 & 74 & \\
\hline $\operatorname{BMI}\left(\mathrm{kg} / \mathrm{m}^{2}\right)^{*}$ & $23.0 \pm 3.4$ & $22.4 \pm 3.1$ & 0.204 \\
\hline Systemic comorbidity & $50(71.4 \%)$ & $173(81.6 \%)$ & 0.070 \\
\hline ASA PS & & & 0.104 \\
\hline 1,2 & 50 & 171 & \\
\hline 3,4 & 20 & 41 & \\
\hline \multicolumn{4}{|l|}{ Laboratory data } \\
\hline Hemoglobin $(\mathrm{g} / \mathrm{dL})^{*}$ & $12.1 \pm 2.0$ & $11.9 \pm 1.9$ & 0.550 \\
\hline $\operatorname{eGFR}\left(\mathrm{mL} / \mathrm{min} / 1.73 \mathrm{~m}^{2}\right)^{*}$ & $69.5 \pm 15.2$ & $68.2 \pm 18.8$ & 0.629 \\
\hline $\operatorname{Albumin}(\mathrm{g} / \mathrm{dL})^{* \dagger}$ & $3.7 \pm 0.7$ & $3.8 \pm 0.5$ & 0.391 \\
\hline Lymphocytes $(\text { cells } / \mu \mathrm{L})^{*}$ & $1635 \pm 654$ & $1606 \pm 583$ & 0.870 \\
\hline Type of gastrectomy & & & 0.049 \\
\hline DG, PPG, PG & 41 & 151 & \\
\hline TG & 29 & 61 & \\
\hline Lymph node dissection & & & 0.893 \\
\hline D0, D1, D1+ & 34 & 101 & \\
\hline D2 & 36 & 111 & \\
\hline Approach & & & 0.068 \\
\hline Open & 59 & 156 & \\
\hline Laparoscopy & 11 & 56 & \\
\hline \multicolumn{4}{|l|}{ Combined resection } \\
\hline Spleen and/or pancreas & $10(14.3 \%)$ & $25(11.8 \%)$ & 0.583 \\
\hline Gallbladder & $14(20.0 \%)$ & $51(24.1 \%)$ & 0.485 \\
\hline Blood loss (mL) & & & $<0.001$ \\
\hline$<320 \mathrm{~mL}^{\ddagger}$ & 39 & 169 & \\
\hline$\geq 320 \mathrm{~mL}$ & 31 & 43 & \\
\hline
\end{tabular}

${ }^{\star}$ Data are presented as means \pm standard deviations

†Serum albumin level data were missing for 1 patient in the complication (+) group and 10 patients in the complication (-) group

${ }^{\ddagger}$ The cutoff value of $320 \mathrm{~mL}$ was calculated using a receiver operating characteristic curve (area under the curve $=0.657$ )

BMI, body mass index; ASA PS, American Society of Anesthesiologists Physical Status; eGFR, estimated glomerular filtration rate; DG, distal gastrectomy;

PPG, pylorus-preserving gastrectomy; PG, proximal gastrectomy; TG, total gastrectomy; DM, diabetes mellitus 
however, only the latter factor was confirmed as a significant predictive factor in the multivariate analysis $(\mathrm{P}=0.025$; Table 6$)$. Although the first factor exhibited a moderate correlation with anastomotic leakage after gastrectomy, this relationship was not statistically significant $(\mathrm{P}=0.09$; Table 6$)$.

\section{Discussion}

Previous studies have identified age as a significant predictive factor for postoperative morbidity after gastric

Table 4 Multivariate analysis of the relationships of overall morbidity with clinical characteristics among elderly patients

\begin{tabular}{|c|c|c|c|}
\hline Characteristic & OR & $95 \% \mathrm{CI}$ & P-value \\
\hline \multicolumn{4}{|l|}{ Sex } \\
\hline Female & 1 & & \\
\hline Male & 1.663 & $0.857-3.377$ & 0.143 \\
\hline \multicolumn{4}{|c|}{ Type of gastrectomy } \\
\hline DG, PPG, PG & 1 & & \\
\hline $\mathrm{TG}$ & 1.275 & $0.684-2.340$ & 0.438 \\
\hline \multicolumn{4}{|l|}{ Blood loss } \\
\hline$<320 \mathrm{~mL}^{*}$ & 1 & & \\
\hline$\geq 320 \mathrm{~mL}$ & 2.538 & $1.344-4.811$ & 0.004 \\
\hline \multicolumn{4}{|c|}{$\begin{array}{l}\text { The cutoff value of } 320 \mathrm{~mL} \text { was calculated using a receiver operating } \\
\text { characteristic curve (area under the curve }=0.657 \text { ) }\end{array}$} \\
\hline \multicolumn{4}{|c|}{$\begin{array}{l}C I \text {, confidence interval; } D G \text {, distal gastrectomy; OR, odds ratio; } P P G, \text { pylorus- } \\
\text { preserving gastrectomy; } P G \text {, proximal gastrectomy; TG, total gastrectomy }\end{array}$} \\
\hline
\end{tabular}

cancer surgery [12-15]. On the other hand, some authors have reported rates of morbidity or mortality in elderly patients similar to those in younger patients [16-19]; however, the morbidity or mortality rate was relatively higher in the elderly group in most of these studies, even when the difference was not statistically significant. The differences in background, including cutoff age, country or study year, might have affected the differences in the results among those studies. In the present study, more patients in the elderly group developed comorbidities and/or exhibited anemia, reduced renal function, poor nutritional status and an ASA PS class of 3 or 4, indicative of reduced organ or physiological functions. Despite the lack of significant differences between the two groups in operative factors, such as the type of gastrectomy, extent of lymph node dissection, combined resection of adjacent organs, or intraoperative blood loss (the exception being open versus laparoscopic surgical approach), the overall morbidity rate was higher in the elderly group $(\mathrm{P}<0.001)$. A multivariate analysis confirmed a blood loss of $\geq 320 \mathrm{~mL}$ as the only risk factor for overall morbidity. This suggests that intraoperative factors have a greater influence on overall postoperative morbidity than do preoperative factors such as the patient's organ functionality or nutritional status. Several studies have also demonstrated that the blood loss volume is a significant predictive factor of postoperative complications in elderly patients $[16,20]$.

The incidence of anastomotic leakage was higher in the elderly group, and a blood loss of $\geq 219 \mathrm{~mL}$ was found to be an independent predictive factor for this complication $(\mathrm{P}=0.025)$. The amount of blood loss during surgery correlates directly with the surgical technique. Inappropriate surgical maneuvers, such as dissection of an incorrect layer or injury to adjacent organs, can cause increased blood loss. Therefore, accurate and careful surgical maneuvers are considered critical to the

$\underline{\text { Table } 5 \text { Univariate and multivariate analysis of factors predictive of cardiovascular complications among elderly patients }}$

\begin{tabular}{|c|c|c|c|c|c|c|}
\hline \multirow[t]{2}{*}{ Characteristic } & \multicolumn{3}{|c|}{ Univariate analysis } & \multicolumn{3}{|c|}{ Multivariate analysis } \\
\hline & Complication $(+)$ & Complication (-) & $\mathrm{P}$-value & OR & $95 \% \mathrm{CI}$ & P-value \\
\hline $\mathrm{n}$ & 7 & 275 & & & & \\
\hline \multicolumn{7}{|l|}{ Sex } \\
\hline Male & 6 & 188 & & 2.950 & $0.475-57.031$ & 0.274 \\
\hline Female & 1 & 87 & & 1 & & \\
\hline ASA PS & & & 0.001 & & & \\
\hline 1,2 & 2 & 219 & & 1 & & \\
\hline 3,4 & 5 & 56 & & 9.336 & $1.893-67.752$ & 0.006 \\
\hline Type of gastrectomy & & & 0.848 & & & \\
\hline DG, PPG, PG & 5 & 187 & & 1 & & \\
\hline TG & 2 & 88 & & 0.761 & $0.103-3.839$ & 0.752 \\
\hline Lymph node dissection & & & 0.206 & & & \\
\hline D0, D1, D1+ & 5 & 130 & & 1 & & \\
\hline D2 & 2 & 145 & & 0.538 & $0.073-2.713$ & 0.464 \\
\hline
\end{tabular}

ASA PS, American Society of Anesthesiologists Physical Status; CI, confidence interval; DG, distal gastrectomy; OR, odds ratio; PPG, pylorus-preserving gastrectomy; $P G$, proximal gastrectomy; TG, total gastrectomy 
Table 6 Univariate and multivariate analyses of factors predictive of anastomotic leakage among elderly patients

\begin{tabular}{|c|c|c|c|c|c|c|}
\hline \multirow[t]{2}{*}{ Characteristic } & \multicolumn{3}{|c|}{ Univariate analysis } & \multicolumn{3}{|c|}{ Multivariate analysis } \\
\hline & Complication $(+)$ & Complication (-) & P-value & OR & $95 \% \mathrm{CI}$ & P-value \\
\hline $\mathrm{n}$ & 13 & 269 & & & & \\
\hline Age (years) & & & 0.017 & & & \\
\hline$<78^{*}$ & 4 & 171 & & 1 & & \\
\hline$\geq 78$ & 9 & 98 & & 2.889 & $0.891-11.102$ & 0.09 \\
\hline Approach & & & 0.039 & & & \\
\hline Open & 13 & 202 & & 1 & & \\
\hline Laparoscopy & 0 & 67 & & $<0.001$ & $0-1.5723$ & 0.989 \\
\hline Blood loss (mL) & & & $<0.001$ & & & \\
\hline$<219 \mathrm{~mL}^{\dagger}$ & 2 & 169 & & 1 & & \\
\hline$\geq 219 \mathrm{~mL}$ & 11 & 100 & & 5.851 & $1.506-38.607$ & 0.025 \\
\hline
\end{tabular}

*The cutoff value of 78 years was calculated using a receiver operating characteristic (ROC) curve (area under the curve [AUC] $=0.668$ )

†The cutoff value of $219 \mathrm{~mL}$ was calculated using a ROC curve (AUC=0.778)

CI, confidence interval; OR, odds ratio

prevention of anastomotic leakage and consequently overall complications. An age of $\geq 78$ years was also found to correlate moderately with anastomotic leakage; however, in a combined analysis with blood loss it became a strong predictor of anastomotic leakage. Among patients with an age of $\geq 78$ years and blood loss of $\geq 219 \mathrm{~mL}$ ( $\mathrm{n}=52), 8$ developed anastomotic leakage $(15.4 \%)$, whereas only 5 patients $(2.2 \%)$ among the other elderly patients $(n=230)$ developed this complication (OR 8.182; 95\% CI 2.557-26.181, $\mathrm{P}<0.001$ ). These findings suggest the criticality of accurate and careful surgical maneuvers in elderly patients, especially those aged $\geq 78$ years.

In this study, an ASA PS class of 3 or 4 was a significant predictive factor for postoperative cardiovascular complications in elderly patients. The ASA PS classification system is a simple, convenient method often used by anesthesiologists to evaluate the general status of patients. Classes 3 and 4 include patients with a history of severe systemic diseases (e.g. cardiovascular or cerebrovascular diseases, current dialysis) [21]. Gupta et al [22] reported that the ASA PS class was a predictor of perioperative myocardial infarction or cardiac arrest, while Mathew et al [23] reported in a systematic review that the risk of postoperative cardiovascular sequelae after non-cardiac surgery was significantly higher among patients receiving dialysis. ASA PS class 3 or 4 was a significant predictive factor for postoperative cardiovascular complications, but was not a predictive factor for overall morbidity in this study. Generally, comorbidities are more common and severe in an elderly population than in a younger population. The proportion of ASA PS class 3 or 4 patients increases in the elderly $(\mathrm{P}<0.001$; Table 1). This study aimed to detect factors predictive of postoperative complications and to determine how to prevent complications in elderly patients; thus, we analyzed the data within the elderly group, in which the proportion of ASA PS class 3 or 4 was higher. This may explain why ASA PS class was not a significant predictive factor for overall morbidity in this study.
In our study, a blood loss of $\geq 219 \mathrm{~mL}$ during surgery correlated with anastomotic leakage, a local complication, whereas an ASA PS class 3 or 4 correlated with cardiovascular events, a systemic complication. These results suggest that while the intraoperative parameter had a strong influence on local complications, the preoperative parameter was more important with regard to systemic complications. Lee et al reported that patient factors, including moderate or severe malnutrition, ASA PS class 3 or 4 , and age of $\geq 60$ years were significant risk factors for systemic complications such as cardiac, vascular, infectious, or pulmonary complications after gastrectomy for gastric cancer [12]. In other words, local complications might be somewhat preventable by the use of sophisticated surgical skills, whereas perioperative control of severe concomitant comorbidities and postoperative care, including intensive monitoring or adequate fluid control, are more important for systemic complications.

Because this was a retrospective study, selection bias is a major limitation. The subjects included only those who agreed to undergo invasive surgery and who had been judged able to tolerate the surgical stress; in other words, some patients, especially elderly patients, might not have undergone gastrectomy because their comorbidities were too serious. Other limitations include the fact that surgeons were not limited to those specialized in upper gastrointestinal surgery, and that laboratory data were missing in some patients. A prospective randomized controlled trial should be conducted to minimize the influence of bias.

In conclusion, the overall morbidity rate was significantly higher in the elderly group and was significantly predicted by an intraoperative blood loss of $\geq 320 \mathrm{~mL}$. In particular, the incidence rates of anastomotic leakage and cardiovascular complications were higher in the elderly group and correlated respectively with a blood loss of $\geq 219 \mathrm{~mL}$ and an ASA PS class of 3 or 4 . 


\section{Summary Box}

\section{What is already known:}

- Age is often reported to be a predictive factor for overall morbidity

- Some predictive factors of post-gastrectomy morbidity have been reported in elderly patients

\section{What the new findings are:}

- We investigated the incidence of each type of postoperative complication along with overall morbidity

- Predictive factors for anastomotic leakage and cardiovascular complications were identified, as well as those for overall morbidity

- We also discussed how to prevent those postoperative complications in elderly patients who underwent elective gastrectomy

\section{References}

1. United Nations, Department of Economic and Social Affairs, Population Division. World Population Prospects: The 2015 Revision, Key Findings and Advance Tables. 2015. Working Paper No. ESA/P/WP.241. pp. 27-31.

2. Statistics Bureau, Ministry of Internal Affairs and Communications. Population Estimates by Age (5 Year Age Group) and Sex. Available from: http://www.stat.go.jp/english/data/jinsui/tsuki/ [Accessed on 2018/5/6].

3. The Editorial Board of the Cancer Statistics in Japan. Cancer Statistics in Japan 2015. Foundation for promotion of cancer research: Tokyo; 2015, pp. 15-23.

4. Endo S, Yoshikawa $\mathrm{Y}$, Hatanaka $\mathrm{N}$, et al. Treatment for gastric carcinoma in the oldest old patients. Gastric Cancer 2011;14:139-143.

5. Endo S, Dousei T, Yoshikawa Y, Hatanaka N, Kamiike W, Nishijima J. Prognosis of gastric carcinoma patients aged 85 years or older who underwent surgery or who received best supportive care only. Int J Clin Oncol 2013;18:1014-1019.

6. Clegg A, Young J, Iliffe S, Rikkert MO, Rockwood K. Frailty in elderly people. Lancet 2013;381:752-762.

7. Dindo D, Demartines N, Clavien PA. Classification of surgical complications: a new proposal with evaluation in a cohort of
6336 patients and results of a survey. Ann Surg 2004;240:205-213.

8. Japanese Gastric Cancer Association. Japanese classification of gastric carcinoma: $3^{\text {rd }}$ English edition. Gastric Cancer 2011;14:101-112.

9. Japanese Gastric Cancer Association. Japanese gastric cancer treatment guidelines 2010 (ver. 3). Gastric Cancer 2011;14:113-123.

10. World Health Organization. Definition of an older or elderly person. Available from: http://www.who.int/healthinfo/survey/ ageingdefnolder/en/[Accessed April 4, 2018]

11. Statistics Bureau, Ministry of Internal Affairs and Communications. Work force among the eldely. Available from: http://www.stat. go.jp/data/topics/topi973.htm [Japanese] [Accessed April 4, 2018]

12. Lee KG, Lee HJ, Yang JY, et al. Risk factors associated with complication following gastrectomy for gastric cancer: retrospective analysis of prospectively collected data based on the Clavien-Dindo system. J Gastrointest Surg 2014;18:1269-1277.

13. Katai H, Sasako M, Sano T, Maruyama K. The outcome of surgical treatment for gastric carcinoma in the elderly. Jpn J Clin Oncol 1998;28:112-115.

14. Kunisaki C, Akiyama H, Nomura M, et al. Comparison of surgical outcomes of gastric cancer in elderly and middle-aged patients. Am J Surg 2006;191:216-224.

15. Hara H, Isozaki H, Nomura E, Fujii K, Sako S, Tanigawa N. Evaluation of treatment strategies for gastric cancer in the elderly according to the number of abnormal parameters on preoperative examination. Surg Today 1999;29:837-841.

16. Takeshita H, Ichikawa D, Komatsu S, et al. Surgical outcomes of gastrectomy for elderly patients with gastric cancer. World J Surg 2013;37:2891-2898.

17. Kubota H, Kotoh T, Dhar DK, et al. Gastric resection in the aged ( $>$ or $=80$ years) with gastric carcinoma: a multivariate analysis of prognostic factors. Aust N Z J Surg 2000;70:254-257.

18. Orsenigo E, Tomajer V, Palo SD, et al. Impact of age on postoperative outcomes in 1118 gastric cancer patients undergoing surgical treatment. Gastric Cancer 2007;10:39-44.

19. Saidi RF, Bell JL, Dudrick PS. Surgical resection for gastric cancer in elderly patients: is there a difference in outcome? J Surg Res 2004; 118:15-20.

20. Kitano Y, Iwatsuki M, Kurashige J, et al. Estimation of Physiologic Ability and Surgical Stress (E-PASS) versus modified E-PASS for prediction of postoperative complications in elderly patients who undergo gastrectomy for gastric cancer. Int J Clin Oncol 2017;22:80-87.

21. American Society of Anesthesiologists. ASA physical status classification system. Available from: https://www.asahq.org/ resources/clinical-information/asa-physical-status-classificationsystem [Accessed April 4, 2018]

22. Gupta PK, Gupta H, Sundaram A, et al. Development and validation of a risk calculator for prediction of cardiac risk after surgery. Circulation 2011;124:381-387.

23. Mathew A, Devereaux PJ, O’Hare A, et al. Chronic kidney disease and postoperative mortality: a systematic review and metaanalysis. Kidney Int 2008;73:1069-1081. 